\begin{tabular}{|c|l|}
\hline Title & Detection and intake assessment of organophosphate flame retardants in house dust in Japanese dwellings \\
\hline Author(s) & $\begin{array}{l}\text { Tajima, Shuji; A raki, A tsuko; Kawai, Toshio; Tsuboi, Tazuru; A it Bamai, Y u; Y oshioka, Eiji; Kanazawa, A yako; Cong, } \\
\text { Shi; Kishi, Reiko }\end{array}$ \\
\hline Citation & $\begin{array}{l}\text { Science of The Total Environment, 478, 190-199 } \\
\text { https://doi.org/10.1016/.scitotenv.2013.12.121 }\end{array}$ \\
\hline Issue Date & 201404 15 \\
\hline Doc URL & http://hdl.handle.net/2115/55347 \\
\hline Type & article (author version) \\
\hline File Information & Tajima_STOTEN.pdf \\
\hline
\end{tabular}

Instructions for use 


\section{Detection and exposure assessment of organophosphate flame retardants in house dust in Japanese dwellings}

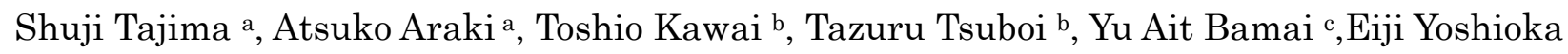
c,d, Ayako Kanazawa a , Shi Cong c , Reiko Kishi a,*

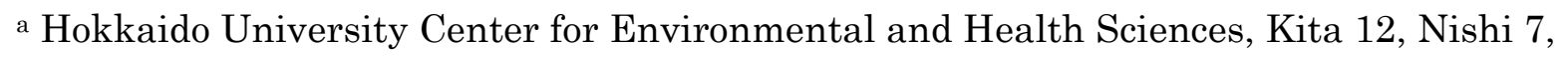
Kita-ku, Sapporo 060-0812, Japan; ' Osaka Occupational Health Service Center, Japan Industrial Safety and Health Association, 2-3-8, Tosabori, Nishi-ku, Osaka 550-0001, Japan; c Hokkaido University Graduate School of Medicine, Department of Public Health Sciences, Kita 15, Nishi 7, Kita-ku, Sapporo 060-8638, Japan; dAsahikawa Medical University, Department of Health Science, E2-1-1-1, Midorigaoka, Asahikawa, Hokkaido 078-8510, Japan

${ }^{*}$ Corresponding author: Reiko Kishi, Professor, MD, PhD, MPH

Hokkaido University Center for Environmental and Health Sciences

Kita 12, Nishi 7, Kita-ku, Sapporo 060-0812, Japan

Tel.: +81-11-706-4748, Fax: + 81-11-706-4725

E-mail: rkishi@med.hokudai.ac 


\section{Abstract}

The demand for phosphorus flame retardants (PFRs) has recently increased as an alternative to polybrominated diphenyl ether (PBDE). PFRs have been detected in house dust, but little is known about the concentrations of PFRs in private homes and the effects on human health. We measured the levels of 10 PFRs in indoor floor dust and upper surface dust from 128 Japanese dwellings of families with children in elementary school. The median (min-max) concentrations $(\mu \mathrm{g} / \mathrm{g})$ of PFRs were as follows: tris(2-butoxyethyl) phosphate (TBOEP), 30.88 (<0.61-936.65); tris (2-chloro-iso-propyl) phosphate (TCIPP), $0.74 \quad(<0.56-392.52) ;$ and triphenyl phosphate (TPHP), $0.87(<0.80-23.35)$. These values exceeded 50\% detection rates, and the rates are median over the LOD in floor dust. The concentrations $(\mu \mathrm{g} / \mathrm{g})$ of TBOEP $26.55 \quad(<0.61-1933.24), \quad$ TCIPP $\quad 2.23 \quad(<0.56-621.23), \quad$ TPHP $3.13 \quad(<0.80-27.47)$, tris (2-chloroethyl) phosphate (TCEP) $1.17(<0.65-92.22)$, and tributyl phosphate (TNBP) 0.74 $(<0.36-60.64)$ exceeded 50\% detection rates in upper surface dust. A significant positive correlation $(\mathrm{P}<0.05)$ between the concentrations of TCIPP and TBOEP was shown in floor dust and upper surface dust $(\mathrm{n}=48)$. Estimated median and 95th percentile daily intake was calculated for toddlers and elementary school children and was compared with reference dose values (RfD) from the literature. For TBOEP, the estimated 95th percentile intake from floor dust was $14 \%$ of RfD for toddlers and $4 \%$ for school children. The estimated intake from upper surface dust was somewhat lower. Estimated median intake of TBOEP and median intake for the other PFRs was less than 1\% of the RfD. TBOEP, TCIPP and TPHP were the main PFRs in the dust. The median levels of PFRs are well below the RfD values. 


\section{Keywords:}

Organophosphate flame retardants (PFRs)

Floor dust

Upper surface dust

Exposure

Reference doses (RfDs)

Elementary school children

Toddler 
Abbreviations:

LOD, limit of detection

PBDEs, polybrominated diphenyl ethers

PFRs, phosphorus flame retardants

PVC, polyvinyl chloride

$\mathrm{RfD}$, reference dose

TBOEP, tris(2-butoxyethyl) phosphate

TCEP, tris(2-chloroethyl) phosphate

TCIPP, tris (2-chloro-iso-propyl) phosphate

TDCIPP, tris(1,3-dichloro-2-propyl) phosphate

TEP, triethyl phosphate

TEHP, tris(2-ethylhexyl) phosphate

TMP, trimethyl phosphate

TMPP, tricresyl phosphate

TNBP, tributyl phosphate

TPHP, triphenyl phosphate 


\section{Introduction}

Phosphorus flame retardants (PFRs) are used as additives to flame retardants and plasticizers and are found in a variety of products. For example, tributyl phosphate (TNBP, CAS number 126-73-8), tris(2-chloroethyl) phosphate (TCEP, 115-96-8), tris(2-chloro-iso-propyl) phosphate (TCIPP, 6145-73-9), tris(1,3-dichloro-2-propyl) phosphate (TDCIPP, 13674-87-8), and triphenyl phosphate (TPHP, 115-86-6) are used as flame retardants in polyurethane foam, thermoplastics, resins, polyvinyl chloride, synthetic rubbers, and textiles (Meeker and Stapleton, 2010). Trimethyl phosphate (TMP, 512-56-1) and triethyl phosphate (TEP, 78-40-0) are used as flame retardants in rigid urethane foam (Daihachi Chemical Industry Co, Ltd.,2013).TNBP, TPHP, and tricresyl phosphate (TMPP, 1330-78-5) are also used as lubricants, and tris(2-butoxyethyl) phosphate (TBOEP, 78-51-3) is often used in floor wax and plasticizers (WHO, 2000). Polybrominated diphenyl ethers (PBDEs) are some of the most extensively used flame retardants; Penta-and Octa-BDE were banned by the European Union in 2003, and their use has voluntarily decreased in the United States as well (van der Veen and de Boer, 2012) because of bioaccumulation (Covaci et al., 2007). In Japan, because PBDEs are being phased out, an increasing number of PFRs and alternative brominated flame retardants are being used (Kajiwara et al., 2011). TCEP, TCIPP, and TDCIPP are used as replacements for penta-BDE (Dodson et al., 2012). The presence of PFRs in indoor dust has been reported in Belgium (Van den Eede et al., 2011), Germany(Brommer et al., 2012), Romania(Dirtu et al., 2012), Spain (Garcia et al., 2007), and Sweden (Bergh et al., 2011), the United States (Dodson et al., 2012), and New Zealand (Ali et al., 2012a), Japan (Kanazawa et al., 2010), Pakistan (Ali et al., 2012b), and Philippines (Kim et al., 2013) . Concentrations of PFRs in indoor dust have been higher than concentrations of PBDEs in recent years (Ali et al., 2012b; Saito et al., 2007; Stapleton et al., 2012).

Only limited reports have been published on the effects of PFRs on human health. TCEP and TDCIPP are carcinogenic in animals, and TCIPP and TBOEP are possible carcinogens (WHO 1998, 2000). TCEP has toxic effects on fetal development in mice (Chapin et al., 1997). 
In animal experimental studies, TBOEP, TCEP, tris(2-ethylhexyl) phosphate (TEHP, 78-42-2), and TDCIPP caused mild irritation to the skin of rabbits (Leisewitz et al., 2000; WHO, 1991b; WHO, 1998; WHO, 2000). TNBP irritates the skin and eyes of humans (WHO, 1991a). One case clinical report described contact dermatitis from exposure to TPHP. The patients had a 6-month history of an itchy fissured psoriasiform dermatitis of both palms. Results of patch test, showed positive to TPHP (Camarasa and Serra-Baldrich, 1992). In epidemiological studies, TDCIPP showed a statistically significant negative association with free thyroxin T4 (Meeker and Stapleton, 2010). Free thyroxin T4 is one of the thyroid function indicator. Increases in TCIPP and TDCIPP concentrations were associated with an increase in the risk of atopic dermatitis, and increases in TNBP concentrations were associated with an increase in the risk of asthma and allergic rhinitis (Araki et al., 2013).

PFRs are known to adsorb to settled dust (Wensing et al., 2005).Over the past 10 years, there has considerable interest in the exposure of vulnerable groups, such as infants, toddlers, and pregnant women, to PFRs to assess the impact on human health related with the indoor environment. Initially, interest in chemicals in indoor environments focused primarily on irritant and toxic properties of individual chemicals (Mercier et al., 2011; Mitchell et al., 2007) and reduce the identified human health risk of poor indoor environment particularly among children (Mercier et al., 2011). As a result, settled dust has been considered an exposure medium (Lioy et al., 2002; Mercier et al., 2011) particularly for infants and toddlers, who are at highest risk for exposure because of frequent hand-to-mouth activities. In addition, elementary school students are considered a high-risk group for exposure to house dust because their body weight is lower and they spend more time at home than adults. In recent years (Ali et al., 2012a; Brommer et al., 2012; Stapleton et al., 2009; Van den Eede et al., 2011), studies have shown that intake (both inhaled dust and eaten dust) to PFRs from dust is 2.5 (mean intake) to 4.0 (high intake) times higher for children than for adults.

Higher PFR concentrations have been detected in Japan than in any other country in previous studies (Araki et al., 2013; Kanazawa et al., 2010). However, these studies 
investigated only new (building age of 3 to 8 years) detached houses. Moreover, there might be differences in use of consumer products, which could be sources of PFRs, between houses with only adult inhabitants and families with young children.

Therefore, the aims of this study were to determine the concentrations of PFRs in indoor floor dust and upper surface dust in houses of families with children in elementary school and to estimate the intake of toddlers and children to PFRs via ingestion of dust in Japan.

\section{Method}

\subsection{Participants and Target}

In this study, we focused on children in elementary school, because most Japanese children attend public school. Therefore, we could expect participation from wide social class.

This study was conducted in 2 phases: a baseline questionnaire in 2008 and a questionnaire, environmental measurements, and a building investigation survey in 2009 and 2010. Selection of the participants was previously reported (Ukawa et al.2012). Briefly, the families of all 6393 schoolchildren from 12 public elementary schools in Sapporo were asked to participate in the study, and the families of 4408 children responded to the questionnaire (response rate of 69.0\%). In total, 832 families (951 children) agreed to allow a home visit to conduct environmental measurements. In 2009 and 2010, we contacted the families of children who were still attending the same elementary school as in 2008, excluding those who did not provide information on the baseline questionnaire regarding the children's gender, grade, or presence of sick house syndrome. This selection procedure identified 128 families who allowed home visits for environmental measurements, dust collection, and completion of a questionnaire in October and November of 2009 or 2010 (Bamai et al., in press). We visited 128 homes but more than 128 allowed home visits. If participants permitted our visiting their homes, we were not able to adjust schedule in some cases by double- booking, because we collected the dust samples own selves.

School buildings which children were going characteristics were investigated by 
questionnaire. One of the 12 schools was excluded because of provisional school building.

\subsection{Questionnaire}

The investigators who visited each dwelling distributed and collected questionnaires for the parents to complete. The questionnaire included queries about the dwelling environment, such as the building structure, age of the building, years of residence, renovations, floor materials, carpet use, and ventilation. One question asked how often the living room floor was cleaned (times/week), and the answers were either (1) 4 times or more or (2) 3 times or less per week.

\subsection{Environmental measurements}

Indoor environmental measurements were performed in all 128 dwellings by well-trained investigators in a main living room where all children commonly spent most of their time. We observed the living room circumstances such as wall materials, floor materials and using electric devices. The Thermo Recorder TR-72U (T\&D Corporation, Nagano, Japan) was used to monitor the room temperature and relative humidity in each house for $48 \mathrm{~h}$.

Dust samples were collected using a previously reported strategy (Kanazawa et al., 2010). Briefly, dust samples were categorized as either floor dust or upper surface dust. Samples of floor dust were collected from the floor surface (floor dust) and from objects within $35 \mathrm{~cm}$ above the floor by vacuuming of surface for $2 \mathrm{~min}$ per $1 \mathrm{~m}^{2}$ floor area. Floor dust and upper surface dust were collected in the whole room because we needed enough dust samples to analyze PFRs concentrations by GC/MS. We vacuumed the whole floor except the furniture which is fixed or too heavy to move. Therefore, the square measure of sampling area was different with each home. Table 1 showed average and standard deviations. After vacuuming, sampling area was measured. Samples of upper surface dust were collected from objects more than $35 \mathrm{~cm}$ above the floor such as furniture, electrical devices, bay window, curtain rail and so on. The vacuum cleaners were with the same power used in this study, because quantity of 
the dust is affected by the power of the vacuum cleaner. The same type of hand-held vacuum cleaner (National HC-V15, Matsushita Electric Works, Ltd., Osaka, Japan) equipped with a paper dust bug (Nichi nich Pharmaceutical Co., Ltd., Mie, Japan ) was used at all dwellings. Unwanted materials such as human and animal hair, insects, food scraps, and scrap paper ware removed by using tweezers. The collected dust was weighed after the removal of unwanted materials.

Trimethyl phosphate, Tributyl phosphate were purchased from Kanto Chemical Co.,Inc. (Tokyo, Japan). Tris(2-chloro-iso-propyl) phosphate, Tris(1,3-dichloro-2-propyl) phosphate, Triphenyl phosphate were purchased from Sigma-Aldrich (St. Louis, MO, USA). Tris(2-chloroethyl) phosphate, Tricresyl phosphate were purchased from Tokyo Chemical Industry Co.,Ltd. (Tokyo, Japan). Tris(2-ethylhexyl) phosphate was purchased from Hayashi Pure Chemical Ind.,Ltd. (Osaka, Japan). tris(2-butoxyethyl) phosphate was purchased from Wako Pure Chemical Industries, Ltd. (Osaka, Japan).

PFRs were analyzed by gas chromatography/mass spectrometry in SIM-SCAN mode with a DB-17 column $(30 \mathrm{~m} \times 0.53 \mathrm{~mm}$ [inner diameter] $\times 1 \mu \mathrm{m}$; J\&W Scientific Inc., Folsom, CA, USA). Table2 shows target ions and qualifier ions. Helium was used as the carrier gas (20 mL/min, constant flow mode) and as a makeup gas $(25 \mathrm{~mL} / \mathrm{min})$. The hydrogen flow was $75 \mathrm{~mL} / \mathrm{min}$. The injector was operated in the splitless mode at $250^{\circ} \mathrm{C}(2 \mu \mathrm{L}$ injection volume). The gas chromatography oven temperature was maintained at $90{ }^{\circ} \mathrm{C}$ for 2 min and then increased at $15{ }^{\circ} \mathrm{C} / \min$ up to $200{ }^{\circ} \mathrm{C}, 5{ }^{\circ} \mathrm{C} / \min$ up to $220^{\circ} \mathrm{C}$, and $20^{\circ} \mathrm{C} / \min$ to $260{ }^{\circ} \mathrm{C}$ and maintained at $260^{\circ} \mathrm{C}$ for $10 \mathrm{~min}$. An internal standard (tris[1H,1H,5H-octaflu-oropentyl]phosphate) was monitored and used for quantification. These analyses were conducted at the Osaka Occupational Health Service Centre, Japan Industrial Safety and Health Association. The background PFR concentrations were measured from the vacuum cleaner and the filter to verify that high PFR concentrations were not detected from these items.

Concentrations of PFRs in upper surface dust were analyzed for all 128 homes visited, 
but concentrations in floor dust were analyzed for only 48 homes visited in 2010 . For the PFR concentrations analyzed in $2009(\mathrm{n}=80)$, LOD values were higher than those analyzed in $2010(\mathrm{n}=48)$ and detection rate were lower than the 2010 dataset. Therefore, we compared the two groups by Mann-Whitney $U$-tests. When concentrations were below the LOD, they were set at half of the detection limit.

\subsection{Quality control / Quality assurance}

The instrumental limit of detection (LOD) was defined as the absolute amount of analytes that yielded a signal-to-noise ratio of $3(n=6)$. The LOD for each PFR in the dust is shown in Table 3; if the PFR concentrations were less than the LOD, they were assigned a value of half the LOD. Recovery tests were performed using wool, cotton, and man-made fiber that imitated dust samples. After $50 \mathrm{ng}$ of each PFR was individually added to 50-mg samples, the air-dried samples were extracted with $1 \mathrm{~mL}$ of acetone and analyzed by gas chromatography/mass spectrometry $(n=5)$. The recovery rate ranged from $86.7 \%$ (trimethyl phosphate [TMP], wool) to $117.5 \%$ (TDCIPP, cotton) (Table A.1 as an appendix).

To avoid PFR contamination, all glass tubes and stainless steel equipment for sample collection and analysis were ultrasonicated for $10 \mathrm{~min}$ in acetone, rinsed with acetone, and then air dried. To examine the background levels of PFRs from materials used for sampling, the vacuum dust bag and the ethanol-soaked cotton used to wipe the vacuum nozzle were extracted with acetone and analyzed by GC/MS to confirm that there were no PFRs peaks (data not shown). Thus, the background level of PFRs was negligible, as described previously (Kanazawa et al., 2010; Saito et al., 2007).

The detection rate was defined as the number of $>$ LOD divided the number of samples.

\subsection{Investigations of $d$ welling characteristics}

In the main living room, we investigated the floor area $\left(\mathrm{m}^{2}\right)$, ceiling height $(\mathrm{cm})$, and interior materials of the floor, walls, and ceiling. Wall and ceiling materials were categorized 
as polyvinyl chloride (PVC) or non-PVC. A non-PVC wall included wallpaper, polywood, and a painted wall. Floor materials were also categorized as wood and others, such as PVC, wall-to-wall carpet, tatami, and stone tiles. Carpet use was categorized as wall-to-wall carpet (all of floor), rug (part of floor), and none. The mechanical ventilation was defined as forced ventilation system automatically by mechanical system. Ventilation equipment was categorized as mechanical ventilation use and mechanical ventilation no use. Mechanical ventilation no use was included there was no mechanical ventilation systems and had the mechanical ventilation systems but did not use the systems.

\subsection{Data analysis}

Potential associations between PFR concentrations in dust and building characteristics were analyzed using Mann-Whitney U test. Carpet use were categorized as yes (wall-to-wall carpet and rug) or no. Building age and years after renovation were categorized as 10 years and more or less than 10 years. Spearman's rank correlation test was used to analyze correlations between the concentration of each PFR in floor and upper surface dust and between PFRs and continuous variables. All analyses were performed using SPSS Statistics 20 (SPSS Inc., Chicago, IL, USA) except regression analysis.

\subsection{Intake assessment}

For intake assessment, we calculated intake ( $\mu \mathrm{g} / \mathrm{kg} / \mathrm{day})$ using equation (1) as follows: Intake $=$ concentration in dust $\times$ dust ingestion $\operatorname{rate}(\mathrm{mg} /$ day $) /($ body weight $[\mathrm{kg}] \times 1000)$

For preliminary evaluation of exposure to PFRs via dust ingestion, we assumed 100\% absorption of intake (Jones-Otazo et al., 2005). We calculated dust ingestion by equation as follows (2) (Wilson et al., 2013):

$$
\mathrm{DIG}=\mathrm{DSL} \times \mathrm{FTSS} \times \mathrm{SA}_{\text {hand }} \times \mathrm{FSA}_{\text {fingers }} \times \mathrm{FQ} \times \mathrm{SE} \times \mathrm{ET}
$$

where DIG $=$ Dust ingestion rate $(\mathrm{mg} / \mathrm{d}), \mathrm{DSL}=$ Dust surface load on horizontal surface 
$\left(\mathrm{mg} / \mathrm{cm}^{2}\right)$. The DSL were separate values and used for hard surface 0.052 (DSLHS) and soft surface 0.139 (DSLss) reported by Wilson et al. (2013). FTSS = Fraction of dust transferred from surface to hand (unitless). The FTSS were separate values and used for hard surface 0.7 $\left(\right.$ FTSS $\left._{\text {Hard }}\right)$ and soft surface $0.14\left(\right.$ FTSS $\left._{\text {Soft }}\right)$ reported by Wilson et al. $(2013)$. SA $_{\text {HAND }}=$ Surface area of one hand (cm2). SAHAND were separate values and used for toddlers 215 and children 295 reported by Wilson et al. (2013). FSAFInGERs = Fractional surface area of the hands (unitless). FSAfingers was used 0.07 reported by Wilson et al (2013). FQ = Frequency of hand to mouth events. FQ were separate values and used for toddlers 16 and for children 9.1 reported by Wilson et al. (2013). SE = Saliva extraction factor (unitless). SE was 0.5 reported by Wilson et al (2013). ET $=24 / \mathrm{h} / \mathrm{d}-$ time outdoors - sleeping time. Time outdoors was used 1.2 and sleeping time was used10.5 for toddler reported by Wilson et al. (2013). Because toddlers spend most of their time indoors, we assumed house dust was the only source of their daily dust intake (Harrad et al., 2008; Van den Eede et al., 2011). ET = At-home time - sleeping time for children. The amount of time these children spent at home each day of $15.14 \mathrm{~h}$ was used the 128 schoolchildren in this study, the sleeping time of $9.34 \mathrm{~h}$ was used the 128 schoolchildren data in this study.

Total Dust Ingestion Rate $(\mathrm{mg} / \mathrm{d})=\left(\right.$ DIGHS $\left.\times \mathrm{FT}_{\mathrm{HS}}\right)+\left(\mathrm{DIGsS}_{\mathrm{s}} \times \mathrm{FT}_{\mathrm{sS}}\right)$ where: $\mathrm{DIG}_{\mathrm{HS}}=$ Dust ingestion rate calculated for hard surfaces $(\mathrm{mg} / \mathrm{d}), \mathrm{FT}_{\mathrm{HS}}=$ Fraction of indoor time spent in contact with hard surfaces (unitless). FTHS was used to 0.5 reported by Wilson et al (2013). DIG $\mathrm{ss}_{\mathrm{s}}=$ Dust ingestion rate calculated for soft surfaces $(\mathrm{mg} / \mathrm{d}), \mathrm{FT}_{\mathrm{ss}}=$ Fraction of indoor time spent in contact with soft surfaces (unitless). FTss was used 0.5 reported by Wilson et al. (2013).

Intake was calculated using the each median values (Table3) of the compound and the 95th percentile (Table3) for worst-case intake scenarios (Van den Eede et al., 2011). Body weight were calculated using a $12.0 \mathrm{~kg}$ which was Japanese 2 years old 75 percentile(Ministry of Health, Labour and Welfare, 2011), and the same amount of dust ingestion was used for toddlers ((Agency, 2011)US EPA, 2011). An average body weight of $32.24 \mathrm{~kg}$ and schoolchildren and the amount of time these children spent at home each day 
$15.14 \mathrm{~h}$ was based 128 schoolchildren in this study. After calculations, dust ingestion was $41.36 \mathrm{mg} /$ day (Toddlers) and $15.32 \mathrm{mg} /$ day (Children). We assumed that intake rate are the same value between floor dust and multi-surface dust. The intake rate may be thought that floor dust is higher than upper surface dust. However, we consumed same value floor dust and upper surface dust, because of worst-case of upper surface dust.

We cited the value of the reference dose (RfD) from previous studies (Ali et al., 2012b; Brommer et al., 2012; Van den Eede et al., 2011). The RfD values were the same in these studies. They calculated RfD based on NOWEL (Hartmann et al., 2004).

\subsection{Ethical considerations}

All study participants gave their written informed consent. The study protocol was approved by the ethical board for epidemiological studies at Hokkaido University Graduate School of Medicine.

\section{Results}

\subsection{Participants characteristics}

The mean value of body weight was $32.24 \pm 8.18 \mathrm{~kg}$, At-home time was $15.14 \pm 1.49 \mathrm{~h}$ and sleeping time was $9.34 \pm 0.60 \mathrm{~h}$. These values were used to calculate dust ingestions.

\subsection{Dwelling characteristics}

Table 1 shows the dwelling characteristics as well as floor and wall materials, because floors and walls can be major sources of PFRs (Wilke et al., 2004). In total, $85 \%$ of the dwellings had wood floor materials and $64 \%$ had rugs; only $8 \%$ had wall-to-wall carpet. The dominant wall type in the dwellings was PVC (88\%); PFRs are contained in PVC and are frequently utilized as flame retardants in plastics, textiles, paints, lacquers, varnishes and building materials (Marklund et al., 2003). 


\subsection{Comparison of floor dust between 2009 and 2010}

Table 3 (a) shows the comparison of PFRs concentrations in floor dust between 2009 and 2010. The $\mathrm{p}^{\text {-values }}$ were $<0.001$ (TCIPP, TEHP, TDCIPP), 0.004 (TPHP). There were significant differences PFRs concentration in the floor dust between 2009 data and 2010 data. $\operatorname{TNBP}(p=0.370)$ and TCEP $(p=0.090)$ were not significant differences but detection rate in 2009 datasets were $6.3 \%$ (TNBP) and 41.3\% (TCEP). The LOD of floor dust were different between 2009 and 2010 data sets. Therefore the floor dust dataset in 2009 was excluded in this study.

The PFRs concentrations of several samples were expected among the LOD differences. For instance, in the case of TCIPP, there was 0.44 ( $\mu \mathrm{g} / \mathrm{g}$ dust) concentration differences between 2009 LOD and 2010 LOD, and several samples seemed to be among the differences. These samples could not estimate relationships between PFRs concentration and dwelling environment and between floor dust and upper surface dust. As the result of Mann-Whitney U test, we decided using 2010 data set only because 2010 data set only use was more LOD values.

\subsection{Detection rate and Correlation of floor dust and upper surface dust with PFRS}

Table 3 shows the concentrations of PFRs and the detection rates. Detection rates in floor dust exceeded 50\% only for TBOEP, TCIPP, and TPHP. TMP, TMPP were not detected in any of the samples. Although TNBP, TCEP, TEHP was detected, but below the 50\% detection rate. The highest concentration of a PFR was TBOEP in floor dust, with an LOD to $936.65 \mu \mathrm{g} / \mathrm{g}$ and a median concentration of $30.88 \mu \mathrm{g} / \mathrm{g}$. The median concentrations of TPHP and TCIPP were 0.87 and $0.74 \mu \mathrm{g} / \mathrm{g}$, respectively. The concentration of TBOEP was approximately 40 times higher than that of TPHP and TCIPP.

Detection rates in upper surface dust exceeded 50\% for TBOEP, TCIPP, TPHP, TCEP, and TNBP, whereas TMP and TMPP were undetectable. The highest concentration of a PFR in upper surface dust was also TBOEP, with an LOD to $1933.24 \mu \mathrm{g} / \mathrm{g}$ and a median 
concentration of $26.55 \mu \mathrm{g} / \mathrm{g}$, followed by TPHP, TCIPP, TCEP, and TNBP. Correlation of upper surface dust and floor dust was investigated for TBOEP, TCIPP, and TPHP, because these PFRs had a detection rate of more than 50\% ( $\mathrm{n}=48)$. A significant correlation between floor dust and upper surface dust was found with TCIPP $(r=0.886, p<0.001)$ and TBOEP $(r=$ 0.630, $\mathrm{p}<0.001)$ but not with TPHP $(\mathrm{r}=-0.018, \mathrm{p}=0.902)$.

\subsection{Floor dust}

Table 4 shows the concentrations of PFRs and their relationship with the dwelling characteristics. Concentrations of TBOEP were significantly different for TBOEP between wood floors $(44.13 \mu \mathrm{g} / \mathrm{g})$ and other floor materials $(1.77 \mu \mathrm{g} / \mathrm{g})$. Concentrations of TBOEP were higher in houses with mechanical ventilation use $(46.74 \mu \mathrm{g} / \mathrm{g})$ than those with mechanical ventilation system no use which include not having mechanical ventilation systems (11.29 $\mu \mathrm{g} / \mathrm{g})$. There was a significant difference in TBOEP concentration in houses, and less than 10 years old were higher than those older than 10 years $(p=0.015)$.

\subsection{Upper surface dust}

Table 5 shows associations of dwelling characteristics and concentrations of PFRs in upper surface dust. Concentrations of TCIPP and TCEP were significantly lower on wood floors than on other materials (tatami, tiles, and wall-to-wall carpet).

Concentrations of TCEP were significantly higher in older houses than in newer houses. there was no significant correlation in buildings with an age $\leq 10$ years $(n=64, r=-0.003, p=$ 0.981). TPHP and TCEP are emitted from televisions and computers (Carlsson et al., 2000; Hartmann et al., 2004; Saito et al., 2007).

\subsection{Comparison of the results of this study with those of previous studies}

Table 6 shows the concentrations of PFRs in this study compared with those in previous studies of private homes because PFR concentrations can vary depending on the sampling 
site (Bergh et al., 2011; Van den Eede et al., 2011). TBOEP concentrations were the highest in Japan, followed by the United States $(11.00 \mu \mathrm{g} / \mathrm{g})$. On the other hand, the TBOEP concentration in houses with wall-to-wall carpet was $2.02 \mathrm{\mu g} / \mathrm{g}$ in this study.

\subsection{Intake assessment}

We performed exposure assessment for toddlers and children using the PFR concentrations in houses of families with children in Japan. Exposure assessment was performed with floor dust upper surface dust and PFRs concentration was used median and 95 percentile each cases. Table7 shows the results of intake assessment. Intake levels of PFRs did not reach any of the RfDs. However, in the scenario of high dust ingestion in the 95 $5^{\text {th }}$ percentile for TBOEP and TDCIPP, the calculated intake level was two-thirds of the RfD.

\section{Discussion}

\section{Association with dwellings (Building materials)}

There are relationship between several PFRs and building materials. These results suggest that building materials are one of the PFRs sources. Especially, floor materials suggest dominant source of PFRs. TBOEP is a component of floor polish and floor finish products (Kajiwara et al., 2011; WHO, 2000). Dirtu et al. (2012) also indicated that the use of waxes containing TBOEP resulted in increased concentrations of this PFR. These findings are consistent with previous studies reporting that TBOEP is the most dominant PFR (Araki et al., 2013; Bergh et al., 2011; Dirtu et al., 2012; Hartmann et al., 2004; Kanazawa et al., 2010; Marklund et al., 2003)

In the case of wall-to-wall carpet, the TBOEP concentration was $2.02 \mu \mathrm{g} / \mathrm{g}($ mean of $\mathrm{n}=3$ ).

Takigami et al. (2009) reported that the TBOEP concentration was $6.6 \mathrm{\mu g} / \mathrm{g}$ in a Japanese-style banquet room in which the floor materials may have been tatami, whereas western-style banquet rooms in the same hotel had TBOEP concentrations of 91-230 $\mathrm{\mu g} / \mathrm{g}$. 
These results confirmed that floor coverings are an important source of TBOEP (Wilke et al., 2004). Thus, more TBOEP may be used as a plasticizer for floor finish products (Kajiwara et al., 2011) than for floor polish for daily use.

From the result of upper surface dust, the concentrations of TCEP in the "others" (Table1: $\mathrm{n}=19)$ in which the dominant material was wall-to-wall carpet $(\mathrm{n}=9)$ and PVC $(\mathrm{n}=$ 8) were higher than in those with wood floors. TCEP is used in carpet and PVC (European Chemicals Agency, 2010).

TPHP did not show any relationship with dwelling characteristics. TPHP concentration was higher upper surface dust than floor dust. These results implicated that the dominant source of TPHP might be on or near upper surface dust, such as consumer products, furniture, and electric devices (Carlsson et al., 2000; Marklund et al., 2005; Sabine Kemmlein, 2003).

\section{Association with dwellings (Building age)}

TBOEP and TCEP show relationship between concentrations and building age. TBOEP concentration was higher in houses less than 10 years old than those older than 10 years. TBOEP concentration greater than the $75^{\text {th }}$ percentile indicated whether the building age was $\leq 10$ years or had been renovated (data not shown). These results indicate that the age of the building and renovations are predominant factors for TBOEP concentrations.

TCEP concentration may be effected by decrease of products. TCEP has been used in building material for acoustic ceilings (Wensing et al., 2005). However, TCEP is currently being replaced by other flame retardants, primarily TCIPP (Marklund et al., 2005), because TCEP has neurotoxic and carcinogenic properties in rats (WHO, 1998). In Japan, production of TCEP had largely decreased by the early 2000s, which was about 10 years before this survey (Saito et al., 2007). To investigate the influence of the decrease in production, we analyzed the correlation between TCEP concentrations and building age $\leq 10$ years and more than 10 years. The results showed that an increased tendency was significant only in the buildings older than 10 years $(n=64, r=0.436, p<0.001)$. On the other hand, in the case of 
building age $\leq 10$ years did not show an increased tendency ( $\mathrm{n}=64, \mathrm{r}=-0.01, \mathrm{p}=0.92)$. This result suggests that lower TCEP concentrations in newer buildings than in older buildings are due to a decrease in production of materials that contain TCEP.

\section{Association with dwellings (Ventilations)}

Concentrations of TBOEP were higher in houses with ventilation equipment use (46.74 $\mu \mathrm{g} / \mathrm{g})$ than those with no use $(11.29 \mu \mathrm{g} / \mathrm{g})$.

In a recent report by Araki et al. (2013), TBOEP concentrations were significantly higher in houses with mechanical ventilation use compared with those no use or not having mechanical ventilation equipment. This result was consistent with our study. Emission rates of PFRs may increase when the concentration of what is in the air decreases, probably because the concentration in dust tends to remain at near-equilibrium with the concentration in the air (Afshari et al., 2004).

\section{Association with dwellings (Cleaning frequency)}

TBOEP concentration was significantly lower cleaning frequency/ week $\leqq 3$ group than $>$ 3group. This result implicated that PFRs concentration become lower with cleaning frequancy/week increasing.

The detection rates of TPHP, TCIPP, TCEP, and TNBP were higher in upper surface dust than in floor dust. One of the reasons may be that the frequency of cleaning upper surface dust may be less than that of floor dust in some households from the hearing of participants.

With a long period of accumulation, PFRs may reach equilibrium easily (Bjorklund et al., 2012); consequently, the concentration of PFRs becomes high.

\section{Methodological considerations}

Although the dust samples were collected in the same room, there were differences of PFRs concentrations between floor dust and upper surface dust. 
Every indoor environment exhibits an unique concentration profile of emitted plasticizers/flame retardants, depending on the furniture, building material, and electronic equipment (Carlsson et al., 1997). In addition, PFR concentrations are influenced by time of use, sampling location, and room type (Dirtu et al., 2012; Takigami et al., 2009). Thus, the sampling site is an important factor in regard to PFR concentrations.

In this study, we did not know dust bug mesh size. It is one of the weak points.

\section{Relationship between PFR concentration and indoor environment.}

TCIPP, TBOEP, TPHP had over the 50\% detection rate in the case of floor dust and TNBP, TCIP, TCEP, TBOEP, TPHP had over the 50\% detection rate in the case of upper surface dust. This result suggests that these PFRs are used in many consumer products and detected with high frequency. There are significant correlations between floor dust and upper surface dust in the case of TBOEP $(r=0.630, p<0.001)$, TCIPP $(r=0.886, p<0.001)$ (data not shown). This result suggests that floor materials are one of the dominant sources of TBOEP and TCIPP. In the case of upper surface dust, there are significant relationships between TCIPP, TCEP, TBOEP concentrations and dwelling environment. These PFRs are used in building materials. This result implicate that PFRs which used in building materials are tend to have the relationships with dwelling environment.

\section{Comparison of the results of this study with those of previous studies}

Comparing PFRs concentration with the previous studies in japan, PFRs concentrations in this study were lower than previous studies in all compounds. This may have been because target houses characteristics were different between previous studies and present study.

Japanese houses have a remarkably high concentration of TBOEP (Araki et al., 2013; Kanazawa et al., 2010) (Table 6). On the other hand, there was no significant difference between TBOEP concentration and the age of the dwelling; this may be because the building age of the target homes in the study by Araki et al. (2013) was 3-8 years. In the study by 
Kanazawa et al. (2010) as well as this study, only dwellings in Sapporo City were investigated. The concentration of TBOEP in floor and upper surface dust was about 50 and 16 times, respectively, lower in our study than reported by Kanazawa et al. (2010).

Dwellings in the study by Kanazawa et al. (2010) were limited to detached houses built within the previous 3 to 8 years, and $92.6 \%$ were wooden structures. Thus, the concentrations of TBOEP may be higher than in this study.

this value is equivalent to the findings in other countries, suggesting that wood floor materials in Japan contain an extremely high amount of TBOEP. When comparing concentrations in upper surface dust in Sweden and Japan, PFR concentrations were in an equal range except for TBOEP, which was higher in Japan than in Sweden.

\section{Intake assessment and Health effect to elementary school children}

High level PERs was detected in Japan, over the RfD was worried to toddlers and children. Intake values for both toddlers and children were several orders of magnitude lower than their RfD.

A similar result was obtained in previous studies (Ali et al., 2012b; Brommer et al., 2012; Van den Eede et al., 2011). The RfD value was based on relatively old toxicological studies (Ali et al., 2012b).

In this study, time aspect of intake assessment was performed not $24 \mathrm{~h}$ but at-home time, because elementally school buildings have not been investigated yet. In addition, dust intake was via eaten dust only and not includes inhaled dust. This under estimate may be one of the reasons.

\section{School building}

The school building which children were going to was relatively old in this study (Table A2).Chemical compounds indoor environment tend to decrease with building age. Moreover, school of PFRs were not expected much variation because Japanese school buildings are 
constructed according to the same guidelines given by the relevant ministries.

\section{Weak points and limitations in this study}

In this study, there were several weak points. First, the dust samples in school building have not collected yet. Therefore intake assessment in school children is not $24 \mathrm{~h}$ intake assessment. Next, we did not know pore size of dust bugs. It is possible that high PFRs concentration dust particle is included in the small dust particle which we have missed. Therefore, in this result appear to underestimate in intake assessment.

There are several limitations in this study too. To generalize in this result is difficult for all population, because of not random population but elementary school children. However, we conducted a survey using questionnaires in 2008 in 4408 public school students (Ait Bamai., 2013). Among these students, 128children participate in this study current study, and the dwelling characteristics of these two were similar. Therefore, in these results is likely to be true for most elementary school children lived in Sapporo. Next, due to insufficient sample size, our study is an underpowered study, and larger sample size may lead to obtain significant p-values.

\section{Conclusions}

This study reported PFR concentrations in house dust that was collected from homes in which elementary school children live. TBOEP, TCIPP and TPHP were the main PFRs in the dust. The different PFRs are associated with different factors. For example, TBOEP, TCIPP, and TCEP concentrations depend on floor materials, and TBOEP concentrations decrease with building age. The TCEP concentration was affected by a decrease in production.

Although there are high concentrations of PFRs (especially TBOEP) in Japan, the median levels of PFRs are well below the RfD values.

\section{Acknowledgement}

This study was financially supported by Japan's Ministry of Health, Labour and Welfare 
through a Health and Labour Sciences Research Grant (H18-Research on Community Health Crisis Management-Ippan-009) and by the Environment Research and Technology Development Fund (C-1151) of Japan's Ministry of the Environment. 


\section{References}

Afshari A, Gunnarsen L, Clausen PA, Hansen V. Emission of phthalates from PVC and other materials. Indoor Air 2004; 14: 120-8.

Agency USEP. Exposure Factors Handbook. 2011.

Ali N, Dirtu AC, Van den Eede N, Goosey E, Harrad S, Neels H, et al. Occurrence of alternative flame retardants in indoor dust from New Zealand: indoor sources and human exposure assessment. Chemosphere 2012a; 88: 1276-82.

Ali N, Van den Eede N, Dirtu AC, Neels H, Covaci A. Assessment of human exposure to indoor organic contaminants via dust ingestion in Pakistan. Indoor Air 2012b; 22: 200-11.

Araki A, Saito I, Kanazawa A, Morimoto K, Nakayama K, Shibata E, et al. Phosphorus flame retardants in indoor dust and their relation to asthma and allergies of inhabitants. Indoor Air 2013.

Bergh C, Torgrip R, Emenius G, Ostman C. Organophosphate and phthalate esters in air and settled dust - a multi-location indoor study. Indoor Air 2011; 21: 67-76.

Bjorklund JA, Sellstrom U, de Wit CA, Aune M, Lignell S, Darnerud PO. Comparisons of polybrominated diphenyl ether and hexabromocyclododecane concentrations in dust collected with two sampling methods and matched breast milk samples. Indoor Air 2012; 22: 279-88.

Brommer S, Harrad S, Van den Eede N, Covaci A. Concentrations of organophosphate esters and brominated flame retardants in German indoor dust samples. Journal of Environmental Monitoring 2012; 14: 2482-2487.

Camarasa JG, Serra-Baldrich E. Allergic contact dermatitis from triphenyl phosphate. Contact Dermatitis 1992; 26: 264-265.

Carlsson H, Nilsson U, Becker G, Ostman C. Organophosphate ester flame retardants and plasticizers in the indoor environment: Analytical methodology and occurrence. Environmental Science \& Technology 1997; 31: 2931-2936.

Carlsson H, Nilsson U, Ostman C. Video display units: An emission source of the contact allergenic flame retardant triphenyl phosphate in the indoor environment. Environmental Science \& Technology 2000; 34: 3885-3889.

Chapin RE, Sloane RA, Haseman JK. The Relationships among Reproductive Endpoints in Swiss Mice, Using the Reproductive Assessment by Continuous Breeding Database. Fundamental and Applied Toxicology 1997; 38: 129-142.

Covaci A, Voorspoels S, Ramos L, Neels H, Blust R. Recent developments in the analysis of brominated flame retardants and brominated natural compounds. Journal of Chromatography A 2007; 1153: 145-171. 
Dirtu AC, Ali N, Van den Eede N, Neels H, Covaci A. Country specific comparison for profile of chlorinated, brominated and phosphate organic contaminants in indoor dust. Case study for Eastern Romania, 2010. Environ Int 2012; 49: 1-8.

Dodson RE, Perovich LJ, Covaci A, Van den Eede N, Ionas AC, Dirtu AC, et al. After the PBDE phase-out: a broad suite of flame retardants in repeat house dust samples from California. Environ Sci Technol 2012; 46: 13056-66.

Garcia M, Rodriguez I, Cela R. Microwave-assisted extraction of organophosphate flame retardants and plasticizers from indoor dust samples. J Chromatogr A 2007; 1152: 280-6.

Harrad S, Ibarra C, Diamond M, Melymuk L, Robson M, Douwes J, et al. Polybrominated diphenyl ethers in domestic indoor dust from Canada, New Zealand, United Kingdom and United States. Environ Int 2008; 34: 232-8.

Hartmann PC, Burgi D, Giger W. Organophosphate flame retardants and plasticizers in indoor air. Chemosphere 2004; 57: 781-7.

Jones-Otazo HA, Diamond ML, Richardson GM. An interagency comparison of screening-level risk assessment approaches. Risk Anal 2005; 25: 841-53.

Kajiwara N, Noma Y, Takigami H. Brominated and organophosphate flame retardants in selected consumer products on the Japanese market in 2008. J Hazard Mater 2011; 192: 1250-9.

Kanazawa A, Saito I, Araki A, Takeda M, Ma M, Saijo Y, et al. Association between indoor exposure to semi-volatile organic compounds and building-related symptoms among the occupants of residential dwellings. Indoor Air 2010; 20: 72-84.

Kim JW, Isobe T, Sudaryanto A, Malarvannan G, Chang KH, Muto M, et al. Organophosphorus flame retardants in house dust from the Philippines: occurrence and assessment of human exposure. Environmental Science and Pollution Research 2013; 20: 812-822.

Leisewitz A, Kruse H, Schramm E. Substituting Environmentally Relevant Flame Retardants: Assessment Fundamentals. Environmental research plan of the German Federal Ministry for the Environment, Nature Conservation and Nuclear Safety 2000.

Lioy PJ, Freeman NC, Millette JR. Dust: a metric for use in residential and building exposure assessment and source characterization. Environ Health Perspect 2002; 110: 969-83.

Marklund A, Andersson B, Haglund P. Screening of organophosphorus compounds and their distribution in various indoor environments. Chemosphere 2003; 53: 1137-46.

Marklund A, Andersson B, Haglund P. Organophosphorus flame retardants and plasticizers in air from various indoor environments. J Environ Monit 2005; 7: 814-9.

Meeker JD, Stapleton HM. House Dust Concentrations of Organophosphate Flame Retardants in Relation to Hormone Levels and Semen Quality Parameters. Environmental Health Perspectives 2010; 118: 318-323. 
Mercier F, Glorennec P, Thomas O, Le Bot B. Organic contamination of settled house dust, a review for exposure assessment purposes. Environ Sci Technol 2011; 45: 6716-27.

Ministry of Health, Labour and Welfare. The Japanese survey of physical development of babies and little children. 2011. (in Japanese)

Mitchell CS, Zhang JJ, Sigsgaard T, Jantunen M, Lioy PJ, Samson R, et al. Current state of the science: health effects and indoor environmental quality. Environ Health Perspect 2007; 115: 958-64.

Sabine Kemmlein OH, Oliver Jann. Emissions of organophosphate and brominated flame flame retardants from selected consumer products and building materials. Atmospheric Environment 2003; 37: 5485-5493.

Saito I, Onuki A, Seto H. Indoor organophosphate and polybrominated flame retardants in Tokyo. Indoor Air 2007; 17: 28-36.

Stapleton HM, Klosterhaus S, Eagle S, Fuh J, Meeker JD, Blum A, et al. Detection of organophosphate flame retardants in furniture foam and U.S. house dust. Environ Sci Technol 2009; 43: 7490-5.

Stapleton HM, Sharma S, Getzinger G, Ferguson PL, Gabriel M, Webster TF, et al. Novel and High Volume Use Flame Retardants in US Couches Reflective of the 2005 PentaBDE Phase Out. Environmental Science and Technology 2012; 46: 13432-13439.

Takigami H, Suzuki G, Hirai Y, Ishikawa Y, Sunami M, Sakai S. Flame retardants in indoor dust and air of a hotel in Japan. Environ Int 2009; 35: 688-93.

Van den Eede N, Dirtu AC, Neels H, Covaci A. Analytical developments and preliminary assessment of human exposure to organophosphate flame retardants from indoor dust. Environ Int 2011; 37: 454-61.

van der Veen I, de Boer J. Phosphorus flame retardants: Properties, production, environmental occurrence, toxicity and analysis. Chemosphere 2012; 88: 1119-1153.

Wensing M, Uhde E, Salthammer T. Plastics additives in the indoor environment--flame retardants and plasticizers. Sci Total Environ 2005; 339: 19-40.

WHO. tri-n-butyl phosphate. World health Organization, Environmental Health Criteria 1991a; 112.

WHO. Triphenyl phosphate. World Health Organization, Environmental Health Criteria 1991b; 111.

WHO. Flame retardants: tris(chloropropyl) phosphate and tris(2-chloroethyl) phosphate. World Health Organization, Environmental Health Criteria 1998; 209.

WHO. Flame retardants: tris(2-butoxyethyl) phosphate, tris(2-ethylhexyl) phosphate and tetrakis(hydroxymethyl) phosphonium salts. World Health Organization, Environmental Health Criteria 2000; 218.

Wilke O, Jann O, Brodner D. VOC- and SVOC-emissions from adhesives, floor coverings and complete 
floor structures. Indoor Air 2004; 14 Suppl 8: 98-107.

Wilson R, Jones-Otazo H, Petrovic S, Mitchell I, Bonvalot Y, Williams D, et al. Revisiting Dust and Soil Ingestion Rates Based on Hand-to-Mouth Transfer. Human and Ecological Risk Assessment 2013; 19: 158-188. 
Table1. Characteristics of the dwelling ( $\mathrm{n}=128)$.

\begin{tabular}{|c|c|c|c|}
\hline Variable & & $\mathrm{n}$ & $\%$ \\
\hline \multicolumn{4}{|c|}{ Building structure } \\
\hline & Wooden & 70 & 54.7 \\
\hline & Reinforced concrete & 58 & 45.3 \\
\hline \multicolumn{4}{|c|}{ Living room investugated } \\
\hline \multicolumn{4}{|c|}{ Wall materials } \\
\hline & PVC & 113 & 88.3 \\
\hline & Others (paper, plywood, etc) & 15 & 11.7 \\
\hline \multicolumn{4}{|c|}{ Floor materials } \\
\hline & Wooden floor & 109 & 85.2 \\
\hline & Wall-to-wall carpet & 9 & 8.6 \\
\hline & PVC & 8 & 6.3 \\
\hline & Tile & 1 & 0.8 \\
\hline & Tatami & 1 & 0.8 \\
\hline \multicolumn{4}{|c|}{ Carepet use } \\
\hline & Wall-to-wall (all floor) & 9 & 8.6 \\
\hline & Rug (a part of the floor) & 84 & 64.0 \\
\hline & No use & 35 & 27.3 \\
\hline \multicolumn{4}{|c|}{ Renovation ( $\leq 10$ years $)$} \\
\hline & Yes & 28 & 21.9 \\
\hline & No & 100 & 78.1 \\
\hline & & Mean & SD \\
\hline \multicolumn{2}{|c|}{ Age of the building (year) } & 13.33 & 10.56 \\
\hline \multicolumn{2}{|c|}{ The living room sampling area $\left(\mathrm{m}^{2}\right)$} & 15.79 & 5.31 \\
\hline \multicolumn{2}{|c|}{ The living room cleaning frequency (times/week) } & 3.97 & 2.05 \\
\hline \multicolumn{2}{|c|}{ The living room Temperature $\left({ }^{\circ} \mathrm{C}\right)$} & 21.12 & 1.99 \\
\hline \multicolumn{2}{|c|}{ The living room relative air humidity (\%) } & 54.87 & 8.66 \\
\hline
\end{tabular}


Table2. Target ion and qualifier ions for GC/MS (m/z).

\begin{tabular}{|l|c|c|}
\hline \multicolumn{1}{|c|}{ PFRs } & Target ion & Qualifier ion \\
\hline TMP & 110 & 140 \\
\hline TEP & 155 & 127 \\
\hline TNBP & 155 & 211 \\
\hline TCIPP & 277 & 201 \\
\hline TCEP & 249 & 251 \\
\hline TEHP & 113 & 99 \\
\hline TBOEP & 199 & 299 \\
\hline TDCIPP & 209 & 381 \\
\hline TPHP & 326 & 325 \\
\hline TMPP & 368 & 367 \\
\hline
\end{tabular}


Table 3. PFRs concentration in dust ( $\mu \mathrm{g} / \mathrm{g}$ dust).

\begin{tabular}{|c|c|c|c|c|c|c|c|c|c|c|c|c|c|}
\hline & \multirow[b]{2}{*}{ LOD } & \multicolumn{6}{|c|}{ Floor $(n=48)$} & \multicolumn{6}{|c|}{ Upper surfaces $(n=128)$} \\
\hline & & 25th\%ile & Median & 75th\%ile & 95th\%ile & $\operatorname{Max}$ & $>\operatorname{LOD}(\%)$ & 25th\%ile & Median & 75th\%ile & 9th\%ile & Max & $>\operatorname{LOD}(\%)$ \\
\hline TMP & 0.51 & $\angle$ LOD & $\angle$ LOD & $<L O D$ & $<$ LOD & $<L O D$ & 0.0 & $<$ LOD & $<$ LOD & $<$ LOD & $<$ LOD & $<L O D$ & 0.0 \\
\hline TEP & 0.26 & $<$ LOD & $\angle \mathrm{LOD}$ & $\angle \mathrm{LOD}$ & $<$ LOD & 0.72 & 0.1 & $<$ LOD & $<$ LOD & $<$ LOD & $<$ LOD & 0.49 & 0.1 \\
\hline TNBP & 0.36 & $<$ LOD & $<$ LOD & 0.41 & 1.91 & 2.46 & 31.3 & $<L O D$ & 0.74 & 1.69 & 6.09 & 60.64 & 69.5 \\
\hline TCIPP & 0.56 & $<L O D$ & 0.74 & 1.96 & 95.40 & 392.52 & 62.5 & 0.82 & 2.23 & 4.95 & 40.37 & 621.23 & 78.9 \\
\hline TCEP & 0.65 & $\angle L O D$ & $<L O D$ & 0.58 & 17.02 & 38.83 & 25.0 & $<L O D$ & 1.17 & 2.28 & 16.07 & 92.22 & 67.2 \\
\hline TEHP & 0.67 & $<\mathrm{LOD}$ & $<L O D$ & $<L O D$ & $<$ LOD & 1.23 & 0.1 & $<L O D$ & $<L O D$ & $\angle$ LOD & 2.32 & 8.16 & 7.8 \\
\hline TBOEP & 0.61 & 3.89 & 30.88 & 96.18 & 615.02 & 936.65 & 97.9 & 12.05 & 26.55 & 80.85 & 383.68 & 1933.24 & 95.3 \\
\hline TDCIPP & 0.59 & $\angle L O D$ & $\angle L O D$ & 33.01 & 563.33 & 9745.02 & 39.6 & $<L O D$ & $<L O D$ & 4.15 & 26.97 & 73.08 & 35.9 \\
\hline TPHP & 0.80 & $\angle$ LOD & 0.87 & 1.61 & 11.09 & 23.35 & 60.4 & 1.95 & 3.13 & 5.48 & 15.99 & 27.47 & 94.5 \\
\hline TMPP & 4.00 & $\angle \mathrm{LOD}$ & $\angle L O D$ & $\angle \mathrm{LOD}$ & $\angle \mathrm{LOD}$ & $\angle \mathrm{LOD}$ & 0.0 & $\angle \mathrm{LOD}$ & $\angle \mathrm{LOD}$ & $\angle \mathrm{LOD}$ & $\angle \mathrm{LOD}$ & $\angle \mathrm{LOD}$ & 0.0 \\
\hline
\end{tabular}

LOD: Limit of detection 
Table 4. Association between the dwelling characteristics and concentration of PFRs in floor dust with an LOD >50\% $\quad(\mu \mathrm{g} / \mathrm{g})$

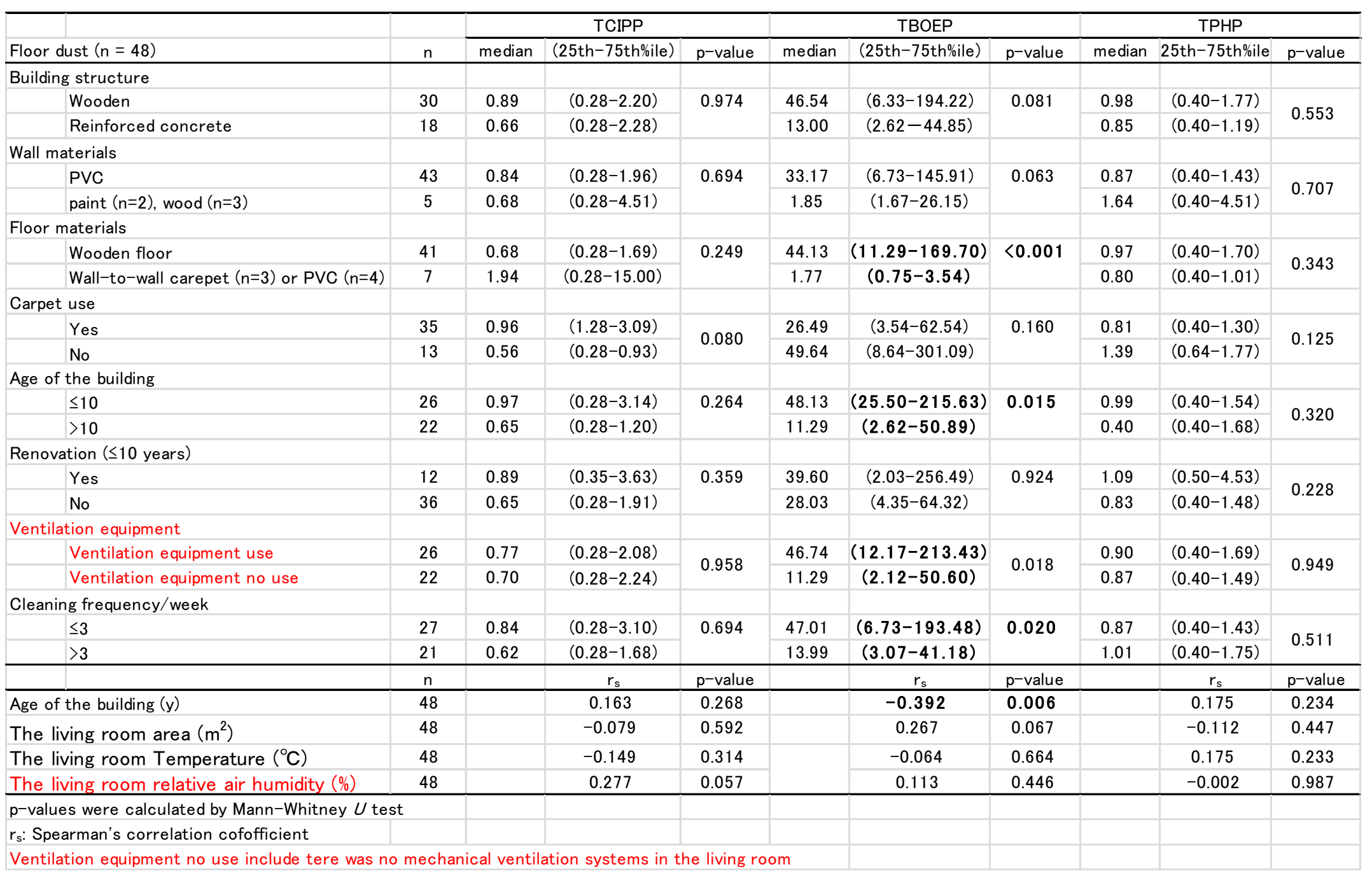


Table 5. Association between the dwelling characteristics and concentration of PFRs in upper surface dust with an LOD >50\% ( $\mu$ g/g)

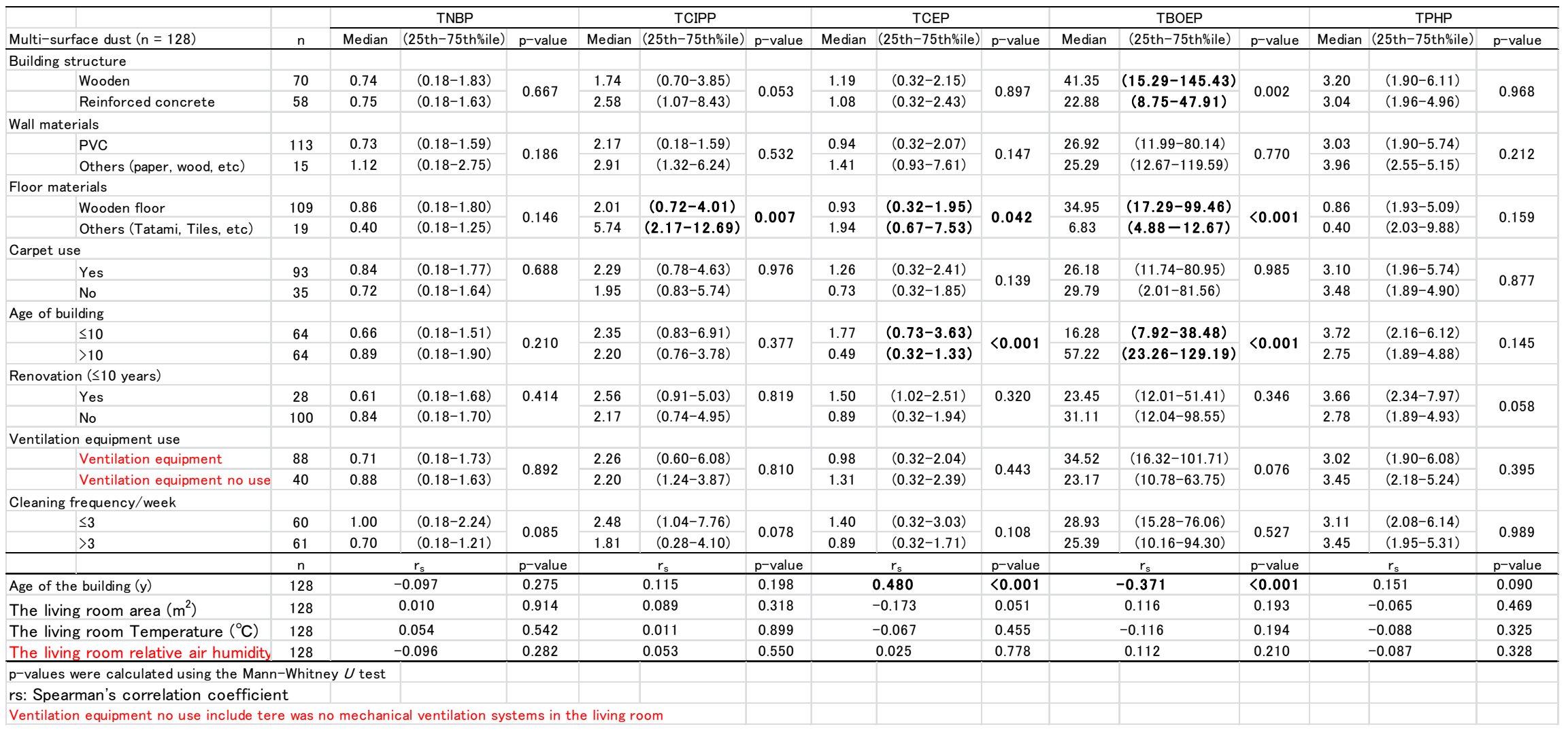


Table 6 Comparison of the median concentrations of PFRs studied in the indoor dust of private homes $(\mu \mathrm{g} / \mathrm{g})$.

\begin{tabular}{|c|c|c|c|c|c|c|c|c|}
\hline Country & $\mathrm{n}$ & TNBP & TCEP & TCIPP & TBOEP & TPHP & TDCIPP & Reference \\
\hline \multicolumn{9}{|l|}{ Floor dust } \\
\hline Japan (in Sapporo) & 48 & $<\mathrm{LOD}$ & $<L O D$ & 0.74 & 30.88 & 0.87 & $<\mathrm{LOD}$ & Present study \\
\hline Japan (in Sapporo) & 41 & 1.40 & 7.50 & 18.70 & 1570.00 & 5.40 & 4.00 & A. Kanazawa et al. 2009 \\
\hline Japan (in 6 regions) & 148 & 1.03 & 5.83 & 8.69 & 508.32 & 4.51 & 2.80 & A. Araki et al. 2013 \\
\hline Spain & 8 & 0.23 & 0.50 & 3.80 & 9.40 & 1.90 & 0.12 & M. Garcia et al. 2007 \\
\hline Belgium & 33 & 0.13 & 0.23 & 1.38 & 2.03 & 0.50 & 0.36 & Van den Eede et al. 2011 \\
\hline New Zealand & 34 & 0.08 & 0.11 & 0.35 & 4.02 & 0.60 & 0.23 & N. Ali et al. 2012 \\
\hline Romania & 47 & 0.05 & n.a. & 0.90 & 1.55 & 0.50 & 0.07 & A. Dirtu et al. 2012 \\
\hline German $^{a}$ & 6 & 0.13 & 0.20 & 0.74 & 0.73 & n.a. & 0.38 & S. Brommer et al. 2012 \\
\hline Pakistan & 31 & 0.01 & n.a. & 0.03 & n.a & 0.09 & n.a. & N. Ali et al. 2012 \\
\hline \multicolumn{9}{|l|}{ Upper surface } \\
\hline Japan (in Sapporo) & 128 & 0.74 & 1.17 & 2.23 & 26.55 & 3.13 & $<\mathrm{LOD}$ & Present study \\
\hline Sweden & 10 & 0.30 & 2.10 & 1.60 & 4.00 & 1.20 & 10.00 & C. Bergh et al. 2011 \\
\hline \multicolumn{9}{|c|}{ Floor and multi-surface } \\
\hline$U_{S A}^{b}$ & 16 & n.a. & n.a. & 0.68 & 11.00 & n.a. & n.a. & R. Dodson et al. 2012 \\
\hline \multicolumn{9}{|c|}{ n.a. Not applicable } \\
\hline \multicolumn{9}{|c|}{${ }^{a}$ PFRs concentration showed by average. } \\
\hline${ }^{b}$ Average betwee & or a & er su & & & & & & \\
\hline
\end{tabular}


Table7. Intake assessment for PFRs.

$\left(\mathrm{ng} \mathrm{kg} \mathrm{kg}^{-1}\right.$ bw $\left.\cdot \mathrm{day}^{-1}\right)$

\begin{tabular}{|c|c|c|c|c|c|c|c|c|c|}
\hline & \multirow{3}{*}{$\begin{array}{c}\text { RfD } \\
\mathrm{ng}(\mathrm{kg} \cdot \mathrm{bw})-1 \mathrm{day}-1\end{array}$} & \multicolumn{4}{|c|}{ Floor dust } & \multicolumn{4}{|c|}{ Upper surface dust } \\
\hline & & \multicolumn{2}{|c|}{ Toddler } & \multicolumn{2}{|c|}{ Children } & \multicolumn{2}{|c|}{ Toddler } & \multicolumn{2}{|c|}{ Children } \\
\hline & & Median & 95th & Median & 95th & Median & 95th & Median & 95th \\
\hline TNBP & 24000 & 0.61 & 6.42 & 0.09 & 0.91 & 2.49 & 20.46 & 0.35 & 2.89 \\
\hline TCIPP & 80000 & 2.48 & 320.78 & 0.35 & 45.27 & 7.48 & 135.74 & 1.06 & 19.16 \\
\hline TCEP & 22000 & 1.09 & 57.23 & 0.15 & 8.08 & 3.93 & 54.02 & 0.56 & 7.62 \\
\hline TBOEP & 15000 & 103.84 & 2068.06 & 14.65 & 291.87 & 89.28 & 1290.18 & 12.60 & 182.08 \\
\hline TPHP & 70000 & 2.93 & 37.27 & 0.41 & 5.26 & 10.51 & 53.75 & 1.48 & 7.59 \\
\hline TDCIPP & 15000 & 0.98 & 1894.27 & 0.14 & 267.34 & 0.94 & 90.70 & 0.13 & 12.80 \\
\hline
\end{tabular}


Table A.1 Recovery test (\%)

\begin{tabular}{|l|c|c|c|}
\hline \multicolumn{1}{|c|}{ PFRs } & Wool & Cotton & $\begin{array}{c}\text { Man-made } \\
\text { fiber }\end{array}$ \\
\hline TMP & 86.7 & 104.3 & 88.0 \\
\hline TEP & 97.7 & 105.5 & 99.7 \\
\hline TNBP & 113.5 & 108.7 & 109.8 \\
\hline TCIPP & 115.2 & 115.9 & 113.0 \\
\hline TCEP & 115.9 & 104.6 & 108.1 \\
\hline TEHP & 115.2 & 104.6 & 110.6 \\
\hline TBOEP & 97.2 & 96.9 & 95.8 \\
\hline TDCIPP & 112.6 & 117.5 & 115.5 \\
\hline TPHP & 95.0 & 90.7 & 88.0 \\
\hline TMPP & 108.5 & 90.0 & 106.0 \\
\hline
\end{tabular}


Table A2.Elementary school building characteristics $(n=11)$.

\begin{tabular}{|l|c|c|}
\hline Variable & $\mathrm{n}$ & $\%$ \\
\hline Building structure & & \\
\hline Rainforced concreate & 11 & 100 \\
\hline wooden structure & 0 & 0 \\
\hline Floor materials (class room) & & \\
\hline Plastic tile & 8 & 72.7 \\
\hline Wooden floor & 2 & 18.2 \\
\hline PVC & 1 & 9.1 \\
\hline Ventilation (class room) & & \\
\hline Natural ventilation (open window) & 8 & 72.7 \\
\hline Mechnical ventilation & 3 & 27.3 \\
\hline & Mean & SD \\
\hline Age of the building (year) $\left(n=10^{b}\right)$ & 28.90 & 12.05 \\
\hline
\end{tabular}

${ }^{a}$ The one of all of 12 was the temporarily school building.

${ }^{b}$ Age of the school building of one school was not clear. 
Table S1. Compare to 2009 and 2010 data set.

$(\mu \mathrm{g} / \mathrm{g})$

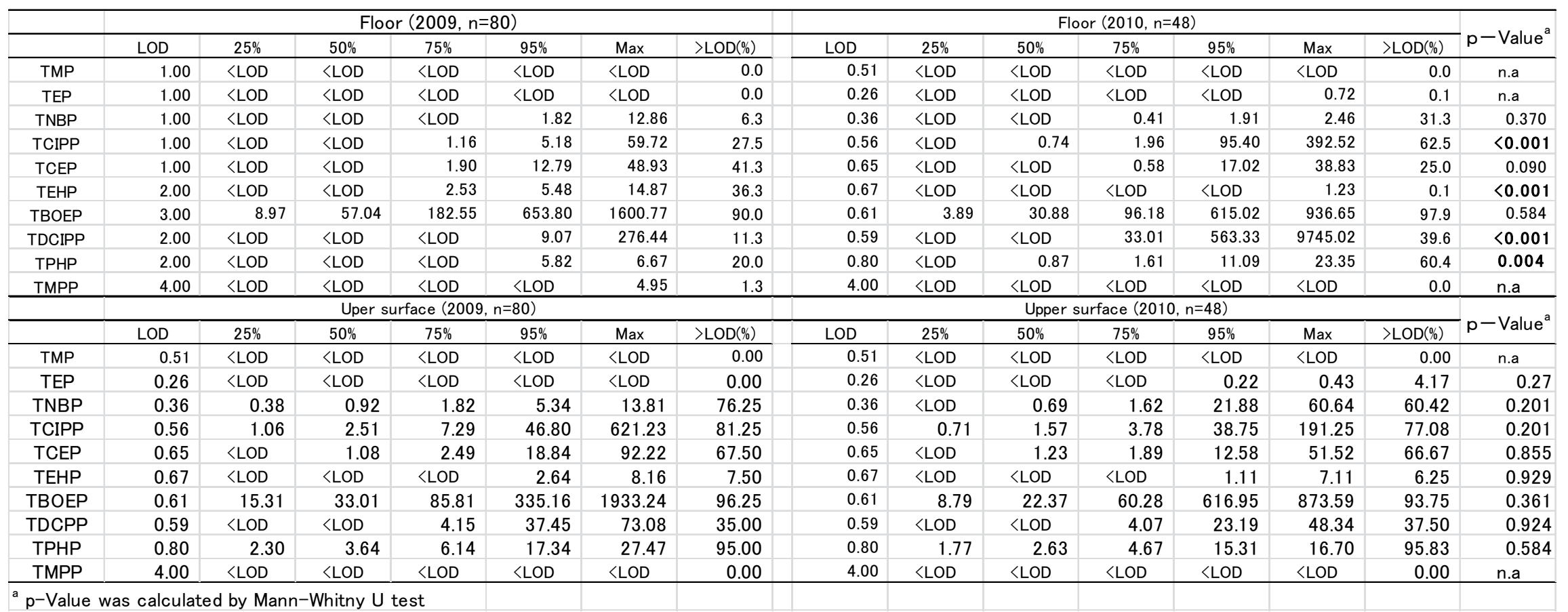

